\title{
Isolation and Characterization of Bioactive Compounds from Medicinal Plants of Ethiopia- A Review
}

\author{
Genene Bekele ${ }^{1}$ and Hazare $\mathrm{ST}^{2 *}$ \\ ${ }^{1}$ College of Natural and Computational Science, Dilla University, Ethiopia \\ ${ }^{2}$ College of Agriculture Biotechnology, India
}

Submission: May 08, 2017; Published: August 24, 2017

*Corresponding author: Hazare ST, Assistant professer, College of Agriculture Biotechnology, Hatta (Parbhani), India,

Email: sunilhajare@gmail.com

\section{Review}

Some plants having the medicinal value in form of chemical substances that produce a definite physiological action on the human body are called phytochemicals. Since the ancient time these phytochemicals are used to cure the disease in herbal and homeopathic medicines. These are non-nutritive substances, have protective or disease preventive property. There arises a need and therefore to screen medicinal plants for bioactive compounds as a basis for further biomedical studies. With advances in phytochemical techniques, several active principles of many medicinal plants have been isolated and introduced as valuable drug in modern systems of medicine. The most important of these bioactive compounds are alkaloids, flavonoids, tannins and phenolic compounds [1]. These are the important raw materials for drug production [2]. Most plants contain several compounds with antimicrobial properties for protection against aggressor agents, especially microorganisms [3]. At present $32 \%$ of drugs are introduced in to international marker which are plant origin [4].

The Ethiopian ecosystem is gifted by a wide range of ecological, edaphic, and climatic conditions that resulted in to wide diversity of its biological resources, both in form of flora and fauna wealth. The plant genetic resources of the country exhibit an enormous diversity as seen in the fact that Ethiopia is one of the twelve Vavilov centers of origin for domesticated crops and their wild and weedy relatives. Recent survey estimated that there are more than 7000 species of flowering plants recorded in Ethiopia, out of which 12 percent are found endemic [5-7].

Medicinal plants contain many essential components, bioactive compounds. In Ethiopia there are 600 species of medicinal plants which may contain disease-curing biocompounds which are distributed all over the country especially, in the south and south-western part of the country. The woodlands of Ethiopia are the source of most of the medicinal plants, followed by the montage grassland/dry montage forest complex of the plateau. Other important vegetation types for medicinal plants are the evergreen bush land and rocky areas. Most of them are confined [8] and have been used as a source of traditional medicine to treat different human and livestock ailments [9].

The medicinal plants and products, minerals has been primary and important source of healthcare in fight against various physical health problems of 85 percent of rural people including poor in urban area [10-12]. The importance and role of these traditional healthcare systems will not diminish in the future because they are both culturally viable, safer to health and expected to remain affordable while the modern healthcare service is both limited and expensive[13-15].

Ethiopia has a long history of traditional healthcare based largely on rich, though unstandardized, pharmacopoeia drawn mostly from plants used both by women in the home in selfadministration and traditional health practitioners (THPs). The efficacy of a few of these plants (Hagenia abyssinica) and Glinus lotoides from the treatment of tapeworm, and Phytolacca dodecandra as a molluscicide in the control of (schistosomiasis) has been scientifically determined, but the safety and efficacy of many others in the treatment of various diseases remains underdeveloped [16-18].

These valuable plant species now a day is endangered due to the several factors like environmental degradation, agriculture expansion, loss of forest and woodland and urbanization. This is alarming signal to the population, which has for generations, relied on these resources to combat the ailments of both human beings and domestic animals. Conventional medical services remain concentrated in urban areas and have failed to keep pace with the growing population, keeping health care access out of reach for most Ethiopians living in Ethiopia. Because traditional 
medicine is culturally entrenched, accessible, and affordable, up to $80 \%$ of the Ethiopian population relies on traditional remedies as a primary source of health care [19-21].

Table 1: Distribution of the medicinal plants by their growth forms (Source- IBC).

\begin{tabular}{|c|c|c|}
\hline Growth Habit & No. of Species & Percent \\
\hline Herbs & 271 & 30.5 \\
\hline Shrubs & 168 & 19 \\
\hline Trees & 110 & 12.4 \\
\hline Climbers & 74 & 8.3 \\
\hline Reed & 2 & 0.2 \\
\hline Unidentified & 262 & 29.6 \\
\hline
\end{tabular}

Table 2: Distribution of medicinal plants by their state of existence.

\begin{tabular}{|c|c|c|}
\hline State of Existence & No. of Species & Percent \\
\hline Wild & 357 & 40.2 \\
\hline Cultivated & 89 & 10 \\
\hline Weed & 52 & 5.9 \\
\hline Undetermined & 389 & 43.9 \\
\hline
\end{tabular}

Table 3: List of Important medicinal plants and disease treated.

\begin{tabular}{|c|c|}
\hline Medicinal Plant & Disease \\
\hline Allium sativum & Malaria \\
\hline Aloe barbadensis & Ascariasis \\
\hline Achyranthes aspera & Tonsillitis \\
\hline Carica papaya L & Hepatitis \\
\hline Citrus aurantifolia & Diarrhea \\
\hline Citrus aurantifolia & Hepatitis \\
\hline Cordia Africana & Acute febrile illness(AFI) \\
\hline Cyphostema acaulata & Snake bites \\
\hline Citrus aurantifolia & Hyper tension \\
\hline Datura stramonium & Tenea versicolor, wound \\
\hline Datura innoxia & Leishmaniasis \\
\hline Dodonaea viscose & Vitiligo \\
\hline Eucalyptus globules & Acute febrile illness(AFI) \\
\hline Entada abyssinica & Herpefoster \\
\hline Euclea natalesis & Rabies \\
\hline Euphorbia tirucali & Tuberculosis(TB) \\
\hline Linum ustatissimum & Swelling around neck(Megegha) \\
\hline Ocimun lamiifolium & Acute febrile illness \\
\hline Phytolacca dodecandra & Abortion \\
\hline Rumex abyssinicus & Hypertension \\
\hline Sida schimperiana & Tuberculosis(TB) \\
\hline Schinus molle & Asthma \\
\hline Solanum insanum & Anthrax \\
\hline Solanum dulcamara & Goiter \\
\hline Trigonella foenum & Spider poison \\
\hline Whithania somnifera & Common cold \\
\hline Zingiber officinale & Abdominal cramp \\
\hline
\end{tabular}

The majority of the medicinal plants are herbs, followed by shrubs and trees (Table 1) Most of the medicinal plant species are found in the wild (Table 2) and therefore, the threats and trends are similar to those of the forest plant species [22]. So that it is a urgent need to preserve these plant species by modern techniques like biotechnology, tissue culture and isolate the important bioactive compounds (List of Medicinal plants Table 3).

\section{Biocompound Extraction Preparation}

All stages of extractions, from the pre-extraction and extraction are equally important in the study of medicinal plants. The sample preparation such as grinding and drying affected the efficiency and phyto chemical constituents of the final extractions; that eventually have an effect on the final extracts. It can be concluded that, no universal extraction methods is the ideal method and each extraction procedures is unique to the plants. Previously optimized methods can be used to lead in the selection of suitable methods. Extraction is the crucial first step in the analysis of medicinal plants, because it is necessary to extract the desired chemical components from the plant materials for further separation and characterization.

\section{Separation and Characterization Methods}

\section{Thin layer chromatography [TLC]}

Thin layer chromatographic (TLC) technique readily provides qualitative information and with careful attention to details, it is possible to obtain quantitative data. Thin layer chromatography is a technique used to separate and identify compounds of interest. A TLC plate is made up of a thin layer of silica adhered to glass or aluminum for support. The silica gel acts as the stationary phase and the solvent mixture acts as the mobile phase. In the ideal solvent system the compounds of interest are soluble to different degrees. Separation results from the partition equilibrium of the components in the mixture $[23,24]$.

In the simplest form of the technique, a narrow zone or spot of the sample mixture to be separated is applied near one end of the TLC plate and allowed to dry. The strip or plate is then placed with this end dipping in to the solvent mixture, taking care that the sample spot/zone is not immersed in the solvent. As the solvent moves towards the other end of the strip, the test mixture separates into various components. This is called as the development of TLC plates. The separation depends on several factors.

a. Solubility: The more soluble a compound is in a solvent, the faster it will move up the plate.

b. attractions between the compound and the silica, the more the compound interacts with silica, the lesser it moves,

c. Size of the compound, the larger the compound the slower it moves up the plate $[23,24]$. 


\section{High performance liquid chromatography}

High performance liquid chromatography (HPLC) is a versatile, robust, and widely used technique for the isolation of natural products [25]. Currently, this technique is gaining popularity among various analytical techniques as the main choice for fingerprinting study for the quality control of herbal plants [26]. Natural products are frequently isolated following the evaluation of a relatively crude extract in a biological assay in order to fully characterize the active entity.

The biologically active entity is often present only as minor component in the extract and the resolving power of HPLC is ideally suited to the rapid processing of such multi component samples on both an analytical and preparative scale. Many bench top HPLC instruments now are modular in design and comprise a solvent delivery pump, a sample introduction device such as an auto-sampler or manual injection valve, an analytical column, a guard column, detector and a recorder or a printer.

Chemical separations can be accomplished using HPLC by utilizing the fact that certain compounds have different migration rates given a particular column and mobile phase. The extent or degree of separation is mostly determined by the choice of stationary phase and mobile phase. Generally the identification and separation of phyto chemicals can be accomplished using isocratic system (using single unchanging mobile phase system). Gradient elution in which the proportion of organic solvent to water is altered with time may be desirable if more than one sample component is being studied and differ from each other significantly in retention under the conditions employed $[25,26]$.

Purification of the compound of interest using HPLC is the process of separating or extracting the target compound from other (possibly structurally related) compounds or contaminants. Each compound should have a characteristic peak under certain chromatographic conditions. Depending on what needs to be separated and how closely related the samples are, the chromatographer may choose the conditions, such as the proper mobile phase, flow rate, suitable detectors and columns to get an optimum separation.

Identification of compounds by HPLC is a crucial part of any HPLC assay. In order to identify any compound by HPLC, a detector must first be selected. Once the detector is selected and is set to optimal detection settings, a separation assay must be developed. The parameters of this assay should be such that a clean peak of the known sample is observed from the chromatograph. The identifying peak should have a reasonable retention time and should be well separated from extraneous peaks at the detection levels which the assay will be performed. UV detectors are popular among all the detectors because they offer high sensitivity and also because majority of naturally occurring compounds encountered have some UV absorbance at low wavelengths (190-210nm) [25].
The high sensitivity of UV detection is bonus if a compound of interest is only present in small amounts within the sample. Besides UV, other detection methods are also being employed to detect phyto chemicals among which is the diode array detector (DAD) coupled with mass spectrometer (MS) [27]. Liquid chromatography coupled with mass spectrometry (LC/MS) is also a powerful technique for the analysis of complex botanical extracts $[28,29]$. It provides abundant information for structural elucidation of the compounds when tandem mass spectrometry $\left(\mathrm{MS}^{\mathrm{n}}\right)$ is applied. Therefore, the combination of HPLC and MS facilitates rapid and accurate identification of chemical compounds in medicinal herbs, especially when a pure standard is unavailable [30].

\section{Phyto chemical screening assay}

Phyto chemicals are chemicals derived from plants and the term is often used to describe the large number of secondary metabolic compounds found in plants. Phyto chemical screening assay is a simple, quick, and inexpensive procedure that gives the researcher a quick answer to the various types of phyto chemicals in a mixture and an important tool in bioactive compound analyses [31-34].

\section{Fourier-transform infrared spectroscopy (FTIR)}

FTIR has proven to be a valuable tool for the characterization and identification of compounds or functional groups (chemical bonds) present in an unknown mixture of plants [35,36]. In addition, FTIR spectra of pure compounds are usually so unique that they are like a molecular "fingerprint". For most common plant compounds, the spectrum of an unknown compound can be identified by comparison to a library of known compounds. Samples for FTIR can be prepared in a number of ways. For liquid samples, the easiest is to place one drop of sample between two plates of sodium chloride.

The drop forms a thin film between the plates. Solid samples can be milled with potassium bromide $(\mathrm{KBr})$ to and then compressed into a thin pellet which can be analyzed. Otherwise, solid samples can be dissolved in a solvent such as methylene chloride, and the solution then placed onto a single salt plate. The solvent is then evaporated off, leaving a thin film of the original material on the plate.

\section{References}

1. Li HB, Jiang Y, Chen F (2004) Separation methods used for Scutellaria baicalensis active components. J Chromatogr B 812 (1-2): 277-290.

2. Mallikharjuna PB, Rajanna LN, Seetharam YN, Sharanabasappa GK (2007) Phytochemical studies of Strychnos potatorum. Lf-A medicinal plant E-J Chem 4(4): 510-518.

3. Mattocks AR (1967) Spectrophotometric determination of unsaturated pyrrolizidine alkaloids. Anal Chem 39(4): 430-447.

4. Farnsworth NR (1994) In: Natural Products and Drug Development. Krogsgaard-Larsen S, Brogger-Christensen S, Kofod H (Eds.), Copenhagen: Munksgaard. The role of Medicinal plants in drug development. pp. 34-45. 
5. Kelbessa E, Demissew S, Woldu Z, Edwards S (1992) In: The status of some plants in parts of tropical Africa. Edwards S, Zemede A, (Eds.), East and Central Africa: NAPRECA No.2. Botany. Some threatened Endemic plants of Ethiopia. pp. 35-55.

6. Mekonen A, Bluffstone R (2007) In: Proceedings of a Policy Workshop organized by Environmental Economics Policy Forum for Ethiopia (EEPFE). Addis A (Ed,). Addis Ababa: Ethiopian Development Research Institute (EDRI). Polices to increase forest cover in Ethiopia. Ethiopia. pp. 35-43.

7. AbbinkJ (1995) Medicinal and ritual plants of the Ethiopian Southwest: an account of recent research. Indi know and Dev Monitor 3: 6-8.

8. Sofowara A (1993) Medicinal plants and traditional medicines in Africa, University of Ife Press ( $2^{\text {nd }}$ edn), spectrum books. Ibadan, Nigeria, p. 320.

9. Giday M, Asfaw Z, Woldu Z (2009) Medicinal plants of the Meinit ethnic group of Ethiopia: An ethnobotanical study. J Ethnopharmacol 124(3): 513-521.

10. WHO (World Health Organization) (2005) Malaria Control Today. Roll Back Malaria Department. World Health Organization. Geneva.

11. WHO (World Health Organization) (2006) Guidelines for the treatment of malaria. World Health Organisation, Geneva.

12. WHO (World Health Organization) (2011) World Malaria Report World Health Organization, Geneva.

13. Tekalign D, Yalemtsehay M, Abebe A (2010) In vivo antimalarial activities of Clerodendrum myricoids, Dedonea augustifolia and Aloedebrana against Plasmodium berghe. Ethiop J Health Dev 24(1): 25-29.

14. Snow RW, Bradley AK, Hayes R, Byass P, Greenwood BM (1987) Does wood smoke protect against malaria? Ann Trop Med Parasitol 81(4): 449-451.

15. Seyoum A, Palsson K, Kunga S, Kabiru E, Lwande W, et al. (2002) Traditional use of mosquito-repellent plants in Western Kenya and their evaluation in semi-field experimental huts against Anopheles gambiae: ethnobotanical studies and application by thermal expulsion and direct burning. Trans Roy Soc Trop Med Hyg 96(3): 225-231.

16. Waka M, Hopkins R, Curtis C (2004) Ethnobotanical survey and testing of plants traditionally used against hematophagous insects in Eritrea. Ethnopharmacol 95(1): 95-101.

17. Abbink J (1995) Medicinal and ritual plants of the Ethiopian Southwest: an account of recent research. Indi know and Dev Monitor 3: 6-8.

18. Abera B (2003) Medicinal plant used in traditional medicine in Jimma zone. Ethiopiopian J of Health Sci 13(2): 85-94.

19. Bekele E (2007) Study on actual situation of medicinal plants in Ethiopia. pp. 54-60.

20. Getahun A (1976) Some common medicinal and poisonous plants used in Ethiopian folk medicine. Addis Ababa University, Addis Ababa, Ethiopia.
21. Desta B, (1994) Ethiopian traditional herbal drugs. Part III: Antifertility activity of 70 medicinal plants. Journal of Ethnopharmacology 44(3): 199-209.

22. Ethiopia's CBD $4^{\text {th }}$ Country Report.

23. Hamburger MO, Cordell GA (1987) A direct bioautographic TLC assay for compounds possessing antibacterial activity. J Nat Prod 50(1): 1922.

24. Sasidharan S, Chen Y, Saravanan D, Sundram KM, Latha LY (2007) Extraction, isolation and characterization of bioactive compound from the seeds of Minusops elengi Linn. Afr J Biotechnol 6(12): 1446-1449.

25. Cannell RJP (1998) Natural Products Isolation. New Jersey: Human Press Inc. pp. 165-208.

26. Fan XH, Cheng YY, Ye ZL, Lin RC, Qian ZZ (2006) Multiple chromatographic fingerprinting and its application to the quality control of herbal medicines. Anal Chim Acta 555(2): 217-224.

27. Tsao R, Deng Z (2004) Separation procedures for naturally occurring antioxidant phytochemicals. J Chromatogr B 812(1-2): 85-99.

28. Cai Z, Lee FSC, Wang XR, Yu WJ (2002) A capsule review of recent studies on the application of mass spectrometry in the analysis of Chinese medicinal herbs. J Mass Spectrom 37(10): 1013-1024.

29. He XG (2000) On-line identification of phytochemical constituents in botanical extracts by combined high-performance liquid chromatographic-diode array detection mass spectrometric techniques. J Chromatogr A 880(1-2): 203-232.

30. Ye M, Han J, Chen H, Zheng J, Guo D (2007) Analysis of phenolic compounds in rhubarbs using liquid chromatography coupled with electrospray ionization mass spectrometry. J Am Soc Mass Spectrom 18(1): 82-91.

31. Kumar GS, Jayaveera KV, Kumar CKA, Sanjay UP, Swamy SMV, et al. (2007) Antimicrobial effect of Indian medicinal plants against acne inducing bacteria. Trop J Pharma Res 6: 717-723.

32. Fing X, Jiang H, Zhang Y, He W, Zhang L (2012) Insecticidal activity of ethanol extract from thirty Chinese medicinal plants against spodoptera exigua. J Med Plants Res 6(7): 1263-1267.

33. Govindarajan M, Sivakumar R, Amsath A, Niraimati S (2012) Larvicidal efficacy of botanical extract against Culex tritaeniorhynchus Giles and Anopheles subpictus Grassi. Eur Rev Med Pharm Sci 16(3): 386-392.

34. Eberhardt TL, Li X, Shupe TF, Hse CY (2007) Chinese Tallow Tree (Sapium Sebiferum) utilization: Characterization of extractives and cell-wall chemistry. Wood Fiber Sci 39: 319-324.

35. Hazra KM, Roy RN, Sen SK, Laska S (2007) Isolation of antibacterial pentahydroxy flavones from the seeds of Mimusops elengi Linn. Afr J Biotechnol 6(12): 1446-1449.

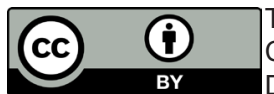

This work is licensed under Creative Commons Attribution 4.0 License DOI: 10.19080/CTBEB.2017.07.555721

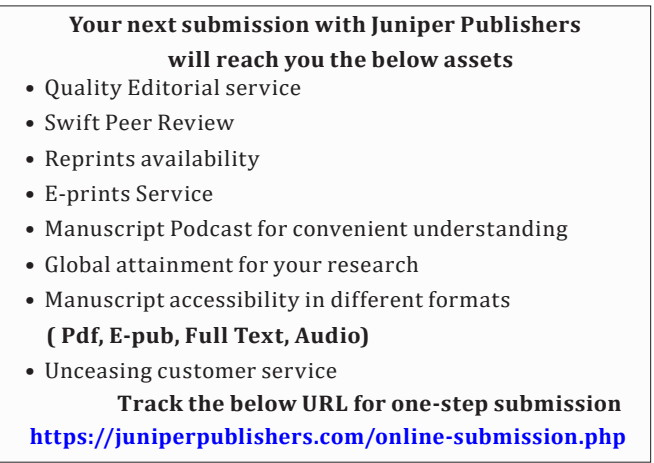

